\title{
Digital vasculitis after splenectomy in a patient with Felty's syndrome
}

\author{
M Comer, R C Bucknall
}

\begin{abstract}
The case is reported of a man with Felty's syndrome in whom digital cutaneous vasculitis developed after a splenectomy. This may be a coincidental occurrence but a possible mechanism is suggested by which the splenectomy may have modified the immunopathology of the disease.
\end{abstract}

(Ann Rheum Dis 1992; 51: 908-909)

Felty's syndrome was first described in $1924^{1}$ as a triad of rheumatoid arthritis, splenomegaly, and leucopenia. It is now recognised to include other features, namely lymphadenopathy, skin ulceration and pigmentation, weight loss, intermittent febrile episodes, normochromic normocytic anaemia, thrombocytopenia, and a mild to moderate haemolytic anaemia. ${ }^{2}$ In common with rheumatoid arthritis manifestations of vasculitis are also notable including mononeuritis multiplex, cranial nerve palsies, and vasculitic rashes. Quantitative and qualitative neutrophil defects give little protection to these patients against the recurrent and fulminant infections which are a further hallmark of the disease.

Felty's syndrome occurs in less than $1 \%$ of patients with rheumatoid arthritis. It predominantly affects patients with severe erosive nodular disease with a high incidence of extraarticular manifestations with serological characteristics of high titres of rheumatoid factor, positive antinuclear factor, hypergammaglobulinaemia, cryoglobulinaemia, and the presence of circulating immune complexes. In such patients Felty's syndrome generally occurs late in the course of their aggressive disease.

The syndrome has been extended to incorporate variant forms of the disease meeting only two of the three cardinal criteria. Felty's syndrome consisting of splenomegaly and neutropenia in the absence of articular manifestations has been reported. ${ }^{3}$ Felty's syndrome incorporating features of rheumatoid arthritis and agranulocytosis but without splenomegaly has also been cited. ${ }^{4}$

Rheumatic Diseases Unit, Royal Liverpool Hospital, Liverpool United Kingdom M Comer

R C Bucknall

Correspondence to: Department of Rheumatology, Medical College of St Bartholomew's, Charterhouse Square, London EClA 7B6,

United Kingdom.

Accepted for publication

6 December 1991

\section{Case report}

A 53 year old man initially presented to the casualty department with a two day history of a painful right ear associated with a yellow discharge from the external auditory meatus. He had been unwell for three months with weight loss, anorexia, recurrent mouth ulceration, and recurrent boils. He had had rheumatoid arthritis since 1981 affecting initially his hands and later his feet. Rheumatoid nodules had major illnesses and there was no family history of rheumatoid arthritis or Felty's syndrome. His treatment at the time of presentation included ibuprofen ( $800 \mathrm{mg}$ three times a day), prednisolone $(2.5 \mathrm{mg}$ three times a day), and dihydrocodeine.

On examination he was pyrexial. Multiple pustules were present on his neck. Angular stomatitis and mouth candidiasis were noted. He appeared anaemic. The arthropathy was quiescent but rheumatoid nodules were distributed over the forearms and Achilles tendons. Splenomegaly of $4 \mathrm{~cm}$ was palpable. Auroscopy revealed a right otitis externa.

Preliminary investigation showed haemoglobin $86 \mathrm{~g} / \mathrm{l}$ and a white blood cell count of $0.9 \times 10^{9} / 1$ with $0.3 \times 10^{9} / 1$ neutrophils. The platelet count was $227 \times 10^{9} / 1$. Urea, electrolytes, blood sugar, and liver function were all within the normal range.

Immunological investigations revealed a positive latex test for rheumatoid factor and the sheep cell agglutination test in a titre of 1600 $\mathrm{IU} / \mathrm{ml}$ and a positive antinuclear factor in a titre of $100 \mathrm{IU} / \mathrm{ml}$ (homogenous type). No cryoglobulins were detected. Complement levels were in the normal range. Hypergammaglobulinaemia was present with an increased IgG concentration of $24.3 \mathrm{~g} / \mathrm{l}$ (normal range less than $14.00 \mathrm{~g} / \mathrm{l}$ ); $\operatorname{IgA}$ and $\operatorname{IgM}$ were also slightly increased at $5.45 \mathrm{~g} / \mathrm{l}$ (normal range less than $4.00 \mathrm{~g} / \mathrm{l}$ ) and $4.0 \mathrm{~g} / \mathrm{l}$ (normal range less than 2.00 g/l) respectively. Immune complexes as detected by the polyethylene glycol technique were in the normal range of $1.4 \mathrm{~g} / 1$ (normal range less than $3 \cdot 2 \mathrm{~g} / \mathrm{l}$ ). Radiological investigation showed early erosive changes in the metatarsophalangeal joints, soft tissue swelling, and periarticular osteoporosis of all the metacarpophalangeal and proximal interphalangeal joints with mild osteoarthritis of the knees and hips.

He received treatment for the staphylococcal otitis externa and an elective splenectomy was performed six weeks later. A $2 \mathrm{~kg}$ spleen measuring $20 \times 20 \times 10 \mathrm{~cm}$ was removed. The histological appearance was consistent with that of Felty's syndrome showing marked congestion of the sinusoids in the red pulp and an inconspicuous white pulp showing small follicles, some of which contained germinal centres.

The recovery after the operation was unappeared in 1985. There had been no other

developed digital vasculitis. Several cutaneous infarcts were present over his fingers and right toes. These lesions appeared a few weeks after the operation and had increased in number over the previous five months.

Laboratory investigation results were as follows: haemoglobin $114 \mathrm{~g} / \mathrm{l}$; white blood cell count $9.8 \times 10^{9} / 1$; and platelets, $533 \times 10^{9} / 1$. Antinuclear antibodies were positive in a titre of 
$100 \mathrm{IU} / \mathrm{ml}$ (speckled type); the sheep cell agglutination test was positive in a titre of $3200 \mathrm{IU} / \mathrm{ml}$; IgG was $14.7 \mathrm{~g} / 1$ (normal range $5 \cdot 00-14.00 \mathrm{~g} / \mathrm{l}$ ), IgA $6.77 \mathrm{~g} / 1$ (normal range $1.00-4.00 \mathrm{~g} / \mathrm{l}$ ), and IgM $2.35 \mathrm{~g} / \mathrm{l}$ (normal range $0.50-2.00 \mathrm{~g} / \mathrm{l}$ ). No immune complexes were detected by the polyethylene glycol technique. In summary there was a reduction in levels of IgG and IgM and an increase in the level of IgA and rheumatoid factor titre after the splenectomy.

\section{Discussion}

The role of the spleen in the pathophysiology of Felty's syndrome has not yet been fully elucidated. The aetiology appears multifactorial but immunological mechanisms, in particular immune complex mediated mechanisms, may be of relevance. Research into Felty's syndrome suggests that the spleen may play a part in such mechanisms.

Splenectomy may have modified immune complex formation, size, physiochemical properties, and deposition in this patient. This could include changes in the components of the immune complex, the antibody or antigen, or may have been the result of the persistence of complexes which may have been taken out of circulation by splenic macrophages. If antibodies produced by the spleen participated in complex formation, or if complex formation had been facilitated in an environment of sluggish splenic sinusoidal flow this may also have had an effect on the course of the disease. With regard to the nature of the antigen, splenic clearance of such molecules may have eliminated the formation of some complexes while an increased antigen load after the splenectomy may have influenced complex size. Alternatively splenic modification of the antigen structure-for example, by enzymatic action-may have changed the valency of the antigen and thus the size of the complex, changing its susceptibility to elimination or propensity to deposit in a particular site.

The nature of the antibody may have similarly been modulated by enzymatic addition or deletion, altering the molecular weight or valency. If the spleen itself is responsible for antibody generation, splenectomy may have an influence on complex components. A shift to a preponderance of a different subclass of antibody whose complex characteristics may differ will also have different effects pathologically. In a study by Jones $e t a l^{5}$ on cutaneous vasculitis activity was closely associated with IgG of a slightly higher molecular weight than that of conventional IgG, suggesting that this represented a small immune complex. Activity was also related to antinuclear antibodies in the complex. Onyewotu et $\mathrm{al}^{6}$ found the presence of IgM enhanced the in vitro uptake of labelled IgG by macrophages. After splenectomy there is impaired synthesis of $\operatorname{IgM}$ which therefore may inhibit uptake of IgG macrophages and increase levels of circulating IgG and the likelihood of formation of intermediate sized complexes which are predisposed to deposition in skin vasculature. Theophilopoulous $e t \mathrm{al}^{7}$ showed that circulating immune complexes containing IgG and low molecular weight IgG may be involved in the pathogenesis of rheumatoid vasculitis. In a study by Conn $e t$ al ${ }^{\mathrm{\gamma}}$ increased levels of $\operatorname{IgA}$, IgM antinuclear antibodies, and C3 were associated with the presence of immune deposits in the skin.

In our patient there was no increase in IgG after splenectomy but instead a decrease. IgM was also decreased but low molecular weight IgM was not determined. The antinuclear antibody titre remained at the same levels as before the operation but the characteristics differed (homogenous before and speckled after the operation). There was, however, an increase in IgA after splenectomy. This was not dramatic but in view of the decrease in IgG and IgM a relative shift to the formation of $\operatorname{IgA}$ complexes or complexes containing a form of antinuclear antibody that differed from the form detected before the operation is possible. The physiochemical peculiarities of such complexes could afford them greater persistence, pathogenicity, or predispose them to deposit in skin vessels. One further effect of splenectomy is a remarkable increase in the white blood cell and platelet counts. It could be argued that this might predispose to an increased thrombotic tendency, perhaps superimposed on a previously subclinical immune complex deposition in the vessels. A reduced flow in the microvasculature could also facilitate in situ formation of complexes in the microvasculature with resultant vasculitis. It has been found that changes in vascular permeability may be mediated by platelet $5 \mathrm{HT}$. ${ }^{9}$ This may be released by platelets interacting with complexes or by platelets traumatised at the site of such initiated inflammation. A thrombocythaemia after splenectomy may predispose to the supranormal release of platelet 5HT and altered vascular permeability which may in turn determine the favourability of deposition of immune complexes which may previously have been destined for other sites or ultimate elimination.

\section{Conclusions}

We have reported the case of a patient who developed digital vasculitis following a splenectomy for Felty's syndrome. We have suggested ways in which the splenectomy may have been instrumental in this development, but accept that the occurrence of the vasculitis at this particular time could have been coincidental.

1 Felty A R. Chronic arthritis in the adult associated with splenomegaly and leucopenia. Fohns Hopkins Medical fournal 1924; 35: 16-20.

2 The Oxford textbook of medicine. 2nd ed. Vol II. Weatherall, Ledingham and Warrell, 1990: 16.8.

3 Heyn J. Non articular Felty's syndrome. Scand 7 Rheumatol 1982; 11: 47-50.

4 Logue G L, Siberman H R. Felty's syndrome without splenomegaly. Am J Med 1979; 66: 703-6.

5 Jones J V, Cumming R H, Asplin C M, Harman R M, Tribe $C R$. Necrotising vasculitis: a circulating immune complex
producing inflammatory skin lesions. Br.7 Dermatol 1975 ; 94: 193 .

6 Onyewotu I I, Johnson G D, Johnson P M, Holborow E J. Enhanced uptake by guinea-pig macrophages of radioiodinated human aggregated immunoglobulin $G$ in the presence of sera from rheumatoid patients with cutaneous vasculitis. Clin Exp Immunol 1975; 19: 267

7 Theophilopoulos A N, Burtonboy G, et al. IgM rheumatoid factor and low molecular weight IgM in association with vasculitis. Arthritis Rheum 1974; 17: 272-83.

8 Conn D L, Schroeter A L, McDuffie F. Cutaneous vessel immune deposits in rheumatoid arthritis. Arthritis Rheum 1976; 19: 15-20.

9 Roitt I. Essential immunologv. 4th ed. Oxford: Blackwell Scientific: 237. 